\title{
Using Literature through the Curriculum, as a Way to Increase Children's Potential
}

\author{
Shqipe Haxhihyseni \\ University "Aleksander Moisiu" Durres, Albania \\ E-mail: shqipeshyti@yahoo.com
}

\section{Doi:10.5901/ajis.2012.v2n4p113}

\begin{abstract}
:
National education system serves as the service sector, which will equip future citizens with the needed skills, making them educated and committed to implementing a national economic plan of development of the country. As seen in pre-university education strategies, educational goals are broad and relate not only to the education and skills development, but with all the personality of the child as well. Within these goals and ways of organizing work has already begun to reform school. In this respect the new curricula claims to introduce new aspects of learning, where the information would not be so important, on the contrary, this information will be seen as a tool for developing valued social and intellectual competence, attitudes and behaviors, which a young man needs in a modern democratic society. Complete curriculum packages displayed by the Institute for the Development of Education seeks a student-centered curriculum, with normalized load, integration accents, a curriculum that fosters critical and creative thinking and other basic skills. It allows students the basic skills of lifelong learning, provides not only subject knowledge but also social skills, life skills, civic values. The prevalence of learning activities professionally called "student-oriented learning 'will be in the center of the learning process planning.
\end{abstract}

Key words: Literature, teaching, learning, ELT.

\section{Introduction}

Student-oriented teaching is already known by teachers and applied successfully by many of them in many schools. This has come as a result of the numerous projects carried out in our country, which were aimed at changing the mentality of teachers on teaching opening new horizons for them. Learner-centered teaching has been implemented in many schools creating the space for an environment where teachers and students openly share ideas freely and communicate with each other.

Introducing a new application models on teaching unlike those traditional ones combined with the diversity of the media supplies children with a wealth of information through the means of communication that are more comfortable and technically more attractive compared to previous years. From this point of view, the work to be carried to the language of literature should be more attractive, which reveals a rich and expressive world of entertainment, through which propelled mental operations that promote reflection on the meaning of the parts, continued use of logic, creativity, increased interest in school activities and long-learned teaching on the subject of Albanian language seems more likely for implementation this teaching, and there are more resources for integrated teaching.

In the framework of the new curriculum for grades 1-6 English language and literature are seen as a single subject that achieve the same goal: enabling students to acquire their language level that enables longlife learning by gaining first linguistic experience, expressing imagination, feelings and attitudes acceptable to intellectual development, enhancing individual development, emotional, aesthetic, moral and spiritual etc., to achieve the following:

- Developing the ability as: to speak, to listen, to read and to write different types of texts, literary and non-literary texts, printed electronics, and grow through these texts critical and creative thinking. 
- Finding, comparing and analyzing information on different texts, adapting them to specific audiences, and integrating them with the students' experiences.

- Possessing knowledge, skills and appropriate stands about Albanian linguistic system, which will enable students to participate successfully in their everyday life.

To reach these goals it is valuable that student-centered teaching and focusing on ways the student participates actively in his learning and acquisition of knowledge through literature and language be primary. Bridging the "what", "why" and "how" students use reading, writing, listening and speaking should be considered the essence of these language programs in schools.

It seems clear that students must use significant materials for the purpose of reading books, instead of filling pages by copying the text word by word and answering questions prepared by the authors of the texts. These goals visualize the classroom environment where students use literature to solve real problems and to communicate with a real audience. But how can we use literature in the classroom to achieve educational goals and achieve the goals by applying learner-centered teaching model and integrated material? This question is precisely intended to get answered on this paper by originally submitting some reflections on the importance of literature and its continuing provision of models that make it possible to promote creative and critical thinking of students.

\section{Reflections on the subject of literature}

Book reading affects drastically the learning and thinking ability of a 6-12 year old child. This should influence teachers to bring literature in the classroom, using reading books as a way of knowledge. During the process of reading and interacting with texts, our affective and cognitive abilities are activated random times, accordingly one time one or another time the other component. So, when we care about something, the level of motivation is high and can read something since we are interested to enrich or develop our knowledge on a particular issue. Once we start to think about the knowledge or knowledge-driven text we immediately engage our affective cognitive baggage.

Currently in our school practice during reading literature classes, the meaning that a teacher gives to the part being read is the only opinion that matters. Students tend to accept the interpretation of the teachers, but there are other times when the meaning is issued during the discussion of the text and this interpretation enriches students with experiences and their way of perceiving things in a different point of view. If all students are to read they will manage to bring ideas and talk about them with each other. One might spend more time to read, but everyone has something to say about what he/she read if the teacher wil encourage critical and creative thinking skills in teaching.

Students can have a lot of fun while reading when it comes to authentic books with rich language and compelling stories of life. Kerr says that "universal themes of literature, good quality literature, including picture books, contain universal themes that make them, in many ways" ageless ".So these books can be enjoyed by students of all ages. (Carr, 2001, p. 146). Students can connect books threads with their lives, can fly with the characters and experience along with the characters. Inclusion of children's literature in the classroom (and not just the parts given in school text) should be already part of the curriculum. Seeing that the Albanian language and literature occupies $23 \%$ of the content of the new curriculum over 9 years of schooling, it is important that this case be given attention, going beyond the textbook, enabling links between books to life experience of students. Books area mirror and a window into life. (Charlotte Huck, 1989) - So, the paper of literature across the curriculum will be an opportunity for students not only make the book links with own experience, finding fulfilling desires, interests and curiosity. All these are important elements to increase motivation in learning and achieving the goals of the new curriculum.

In school, we often focus on the knowledge and mind, and fail the links to student life, while literature helps precisely for this, reconnecting the thoughts with feelings. Literature connects us with life experiences of other countries, different time periods, ways of life; literature helps to understand that there are other ways of living life. Addressing a topic from different perspectives (angles Keeton data through literature), including 
picture books, makes this possible. In addition, the use of literature to learn curricular concepts helps link the concepts taught to real life, bringing the concept within the child's world. (Whitin, 1992, p. XII)

But what to read? The choice is essential reading. School Experience shows that students usually read parts recommended by the authors of textbooks, or parts recommended by the teacher in extracurricular reading classes. Little space is left to the choice of students for the books that should be read in school. If students will be given a choice, then students would be better able to choose the books about their interests and experiences that are meaningful to them. If they could choose, reading can become a meaningful experience in their lives. In every class there are students with interests, needs and experiences of all kinds, so choosing good books is necessary, in order to come as close to these experiences, interests and desires of children. If we restrict forcing children to read only at the guide level then they will not consider reading as necessary to their work or to get information, but will consider it merely as a school task. Today, the literature goes beyond reading the letters. New literature includes media, technology, information and critical literature and can find ways to encourage reading and its connection with science, treating appropriately through the curriculum.

\section{Using literature to achieve educational goals in school}

Curriculum integration is one of the guiding principles of university education in the new curriculum. In this respect, the presentation of the material in the books in a given context should be taken advantage of to be successful in the classroom. This can be achieved if teachers bring to the classroom good books that fit the content of the subjects in the class to use them in different ways. If it is a good book, it can cause different types of ideas that can become familiar in the classroom, encouraging children to compare, to help them understand the content of what is the best book. These comparisons allow students to give their critical thinking to unfold their creative skills.

Some authors of children's books make a wonderful connection between the different subject areas in their books. Good literature captivates the interest of the child and information quickly absorbed through them. (Butzow, 1989, p. 6). Seen in this context the comparison of two books on the same subject is a type of activity not only interesting, but also scientific. The format of the contents of a book can inspire ideas or teaching a lesson demanding, and not in a very casual way, because every writer of a book has developed principles for the book informative enough to draw the attention of readers. Every teacher should be based on this fact, but it certainly should use the criteria for the selection of these books by choosing age appropriate, clear and well organized ones.

Also a newly published book can have more effect than an old publication. Teachers should be aware of the interests of children or the desire to recognize a theme. In the selection of books, the most important thing for teachers is to be able to see the books to decide how to assess this book with those of its kind. Even the children have to go to the library and choose their books on the topic, as it allows them to make their own judgments.

Through literature students can establish a connection to a powerful learning and understanding. Think of a teacher who treats a traditional lesson by reading the students' questions after questions for creating statements that are thought to represent understanding, while for a given reader, the text may or may not be friendly and impossible to understand. Text difficulties are rooted in conceptual complexity and language difficulties that can effectively block full understanding or to make it difficult and unpleasant.

The purpose of the development of reading skills is to enable students to become active readers throughout their lives, able to engage in independent reading activities. Contemporary experience shows that are affirmed literature traditions, in an effort to liberate major literature power as a means to expand the knowledge of students with their own lives and the world around them as a means to sharpen their critical skills, which should be reflected in the manner of work on reading texts in our schools. 


\section{Learning through the curriculum (based thematic lessons in literature)}

Integrated curriculum can bring a range of benefits for teachers and students, using learning topics, projects, units covering diverse materials and providing efficient concepts and skills. These benefits include a better coverage of the curriculum, the use of natural learning, build student interest, teaching more flexible in concrete, understandable and organization of the project plan. Models listed below are supported specifically in integrated curriculums.

\section{A. Models of collaborative thematic units}

Models of collaborative thematic units were built by accepting Gardner's theory on multiple intelligences. This is a model of an integrated thematic units cross-curricular based on the use of literature in the classroom.

To build such a thematic unit we must use some components as below:

1. Themes. Choosing an appropriate theme reflecting the themes of the text (the curriculum, students' interests, experiences, issues or problems)

2. Adjusting the level of the class.

3. Focus. Concentration in a sentence that sums up and directs unit goal

4. Objectives. Identify 3 or 4 goals you want your students to reach at the end of each unit. These can be related to stated objectives and powers.

5. Materials and resources. It is highly beneficial to determine all necessary materials and resources after the unit is written. So avoid the limitation of teachers in several diverse issues known and familiar to them.

a. Printed sources. Newspapers, pamphlets, notes, travel guides, journals, diaries, letters, maps, advertisements, brochures, advertising flyers, encyclopedias, dictionaries, professional journals.

b. Sources: computer, CD-ROM, educational software, educational games and simulations related to curriculum.

c. Internet sources.

d. Audio-visual resources, films, tapes, books, CDs. of. Community resources: guests, trips etc.

e. Instructive television sources.

f. Literature sources: artistic poetry.

Given all of these elements for organizing collaborative thematic units one must organize :

1. General activities that cover all areas of the curriculum reflecting the elements of language and reading program.

2. Discussion topics to make possible the development of divergent opinion on different topics using both open-ended questions and closed ones.

3. Selection of books related to the thematic unit, previously held a variety of activities cross-curricular learning and discussion. The selection of books should certainly include the variety of literary genres.

4. Final activity that may be a project or activity that engages students in meaningful summary of their findings and leads to new ideas, understanding and respect.

5. Evaluation in this case can be achieved by the student's file, grade papers and open debate or miniconferences.

\section{Students benefits from the use of cooperative thematic teaching units}

Thematic units may be arranged around a book or a subject of interest for small children. Many skills, including standards are easily integrated into a studied topic. This way the students during the activities mentioned above will apply a variety of strategies for understanding, interpreting evaluating text, using their experiences, interactions with others, not only as a reader but as a writer, show their understanding of words 
and other texts, their word identification strategies, their understanding of text features (sentence structure, context, graphics). Also students will regulate the use of speaking, writing, and visual language (tradition, style, vocabulary) to communicate effectively with a variety of audiences and for different purposes. Students will apply the structure language, language traditions (pronunciation, punctuation) media techniques, figurative language for creating wide, critique and discuss printed and unprinted texts. They will be able to develop an understanding and respect for diversity in language use, examples, dialect through cultures, ethnic groups, geographic regions and social roles. In addition, students will participate as members of creative, critical, reflective, informed readers community using written language, spoken and visual for the fulfillment of their purpose (for learning, enjoyment, persuasion and the exchange of information ).

\section{B. Working with topics}

Another way of using children's literature in schools is working with themes. This method is suitable for integrated work including more than one subject and is based on a dialogue between teachers and students; students refer themselves of their environment and cooperate with each other. To accomplish this work every teacher should know the course requirements and use them in work assignments, always emphasizing the content.

Preparing to work with topics must pass through several stages, listed below:

1. Defining the topic

2. Duration (minimum one week)

3. Defining the knowledge, skills that students must master in this period; relying program objectives and content.

4. Planning the organization of work.

5. Planning the content, activities, guests, material.

6. Planning activities that students will perform in group, individually and with the entire class (including excursions)

7. Role of class usage (class furniture placement, the introduction of child work, new materials that will be brought)

After this prediction for the work to be carried out the instructor should always be open to surprises, dealing with the ideas brought by students and activity changes depending on the interests of students. An early start of working with themes, topics may include the following:

1. Opening dialogue with students on the topic (brainstorming)

2. Knowing the tale or book

3. Discuss with the class

4. Giving tasks and implementation of the activities planned by the teacher

5. Assessment of the work done.

This method can be used at any age level by adjusting the activities to be carried out to the level of students. This method is functional to study today's society and the environment and to come closer to what is now required by the school: student-centered teaching and development of critical and creative thinking.

\section{Non-literary texts and their effective use in the classroom}

In both models given above work of literature in all its genres is evident, but teachers traditionally believe in school textbooks for the content of materials, forgetting that many fiction books attract readers with elements of surprise and suspicion, which somehow introduce the reader to intrigue and can be successfully used in the classroom to achieve learning and educational goals. A good history is a teaching tool, which provides a specific perspective of learning or thinking about a topic (Carr, 2001, p. 147). Thus: A piece of text can provide the basis for studies: geography, history, science or environmental studies. 
Settings and pictures, located through the index can be used to add meaning to the discussion on a topic. Also a drawing or sketch can be used to support or refer arguments in the debate on social issues, environmental, geographical or historical themes.

In the new programs of the Albanian language in addition to literary texts even non- literary texts is given a considerable importance, to make them a meaningful part of children's literature programs. But in their work can be posed problems, as teachers may not realize that non-literary books are interesting and convenient. On the other hand some who are fans of literature and have not given themselves the opportunity to read non fiction literature, can have this opinion, but reading non fiction literature can be attractive and useful for students. These books can be a challenge for young readers in such way that fiction books are not. These books can offer students:

- Examples of the use of grammar and style used for certain purposes.

- Explorations in the dictionary.

- Appropriate applications forms of punctuation

- Innovative use descriptive tools

- Techniques used by writers to organize and present information

Non fiction literature is an excellent resource for meaningful content in science lessons as well as in any other area of the curriculum; although teachers may have more questions, because usually the book includes his literary side, often overlooked details scientific information that can be very useful for the student. These books provide an opportunity for the promotion of literature on those ways that fiction cannot use. Non-fiction books are the first source of information and social beliefs. Through them children can learn:

- Differentiate between fact and fiction, or the fact and opinion

- Identify the author's goals

- Understand that different authors use different means to influence the reader

- Question the text information

- Understand that any text is written from a point of view

- Have faith in the value of their knowledge, their understanding and view that they bring to the text.

In this way, through the operation of a text students can:

- Make allegations content about the style of the book

- Discuss what they know about the topic

- To suggest new information that they can learn brainstorming questions, which are answered in the text.

- To observe the organizational features of the text as a model for script reading

- Reading of the text with teachers and independently

- To read the titles of the chapters and discuss the information given

- To observe the differences between pictures and different kinds of drawing colors.

- Read words, phrases and sentences that can be focused individually

- To become aware of the features of the text and the style they can use in their writing.

- Recall their observations through drawings of what they have learned, make models, take part in the game

- Discuss, argue the meaning of the content and control the meaning of words in the dictionary.

- Discuss their understanding with descriptions by allowing them to write informative texts themselves.

Older students can:

- Make a more sophisticated level than those younger.

- Read, observe, discuss and use various text features in their writing

- Locate and recognize the text features in other books.

Using these strategies can develop further research information. The children work individually or in a group to organize information appropriate to a topic and write questions that could become the basis for further research. Also they can renew the book style, using it as a model for writing about a topic that they 
have chosen, write an encyclopedia about themselves on a topic of their choice, a procedural text, or writing a guide.

The use of literature based on the above models enables through various activities organized by the teacher to move on the expansion of the text, adding other notes in an existing book, adding drawings and charts, as well as additional details from interviews with adults. Also the children's experiences should not be forgotten and can be added to the text. Search and research are the main activities in these kind of models, and as such significantly affect the development of active thinking, critical and creative, experimenting with different writing styles depending on the purpose.

Another interesting element to be taken into consideration is the creation of quizzes. Students can write questions, whose answers can be found in an informative book. These questions can be stored as paper quizzes and can serve as a resource for games staged. The answers can be written on the opposite side of quizzes and may include book and website in which they are found. This experience makes children keen to be inserted within the structure of some text and enables in delivering answers to different questions. After the use of a text, students can write or illustrate an aspect that seems more interesting to list the facts that they are able to understand, and can choose to write a text itself for a similar topic using different path from that of the model.

During the development of these models in class the children can listen to classical music while they are hearing the story, involving numerical and scientific information on the topic, as well as the inclusion of preferences for animals, plants and other parts of the natural environment and illustration Book.

\section{Conclusions}

This paper focuses on the importance of literature for children, the responsibility of teachers in the development of different subjects integrated with the literature and the responsibility to ensure the pleasure of reading in children. Teachers are those who need to explore creative ways to present literature and become familiar with the ways of looking at how to make decisions about the books that would include in their class. The aim is for students to read books of various genres, such as: alphabet books, books realistic fiction, historical fiction books, science fiction books, biographies, etc., (to complete this task teachers have to spend a lot of time in reviewing children's books) they should be able to examine, evaluate, discuss and use literature and no printed materials for children to explore strategies to use literature activities through curricula and to introduce children to literature. In any case it must be taken into account also the adaptivity to be made for children with disabilities. To achieve an effective use of children's literature in the classroom to achieve educational goals and to meet the needs and interests of the child the teacher should:

- Be familiar with the quality of books

- Be familiar with the standards of reading

- Learn specific ideas for integrating literature in the curriculum

- Recognize the multicultural literature

Use online resources

- To improve how to use children's literature as a pedant about writing 'to learn how to use literature for the teaching of different subjects

- Learn how to develop a plan for reading books during the summer

In this way, the student will be able to:

- Explain the value of children's literature

- Discuss the history of children's literature

- Evaluate and select appropriate literature to bring to class

- To evaluate, rate the illustrations made in children's literature

- Develop strategies to increase the interest of children's literature

- Develop strategies for drama

- Develop the ability to prepare lessons including children's literature. 
The modernization of the school system should be carried out at different levels, as the school system is independent. All institutions are connected to a chain, passing by Parliament, Ministry of Education and Science, Institute ff Education Development, universities, Regional Directorate of Education and schools. If changes will be successful, it will be important to be working on many levels at the same time. Today, the teacher is put before the election: the continuation of the traditional classroom, sticking pedagogical apparatus requirements texts of books which is easier for the teacher, but for the student turns into a boring routine. Alternative to this is what experiments the successful implementation by teaching students contemporary skills that has shown success in developed countries. Heritage has shown great value, but in today's conditions where society aims to play a major role in individual freedom, equality before the law, the importance of individual dignity and opportunity to every individual to develop as well as it allows his talent, his interests skills, must work to achieve these goals by maintaining effective teaching and contemporary.

Environment created in the classroom must be able to respond to students' needs diversity and models implemented in the classroom need to develop critical thinking skills requesting information search, using materials that schools make available. Teacher and students should be able to gather all possible resources from abroad, through various informative networking opportunities, become sources of information and academic counseling.

Creating such an environment can be beneficial by many students. They will try to discover the world from their perspective, build their ideas on it. The use of literature through the curriculum is one of the ways to increase the child's potential, by not only conceiving teaching as providing a certain knowledge, but as a process that propels children's potential, exploits, develops active thinking, independent and creative, stimulating interest trends by leading gradually self-learning and further self-education therefore preparing them to use this learning to continue growing in the new situation, in practice in life.

\section{References}

Butzow, Carol M.\& Butzow, John W. (1989). Science through children's literature. Englewood, Colorado: Teacher Idea Press.

Carr, Kathryn S., \& Buchanan, Dawna L. \& Wentz, Joanna B. \& Weiss, Mary L. \& Brant, Kitty J. (2001). Not just for primary grades: a bibliography of picture books for secondary content teachers. Journal of Adolescent \& Adult Literacy, 45 (2), p146-153

Huck, C. S. (1989). "No Wider Than the Heart is Wide." In J. Hickman \& B. E. Cullinan (eds.), Children's Literature in the Classroom: Weaving Charlotte's Web (pp. 252-262). Needham Heights, MA: Christopher-Gordon Publishers, Inc.) Whitin David J. \& White, Sandra (1992). Read any good math lately? Portsmouth, NH: Heinemann Educational Books. http:// www.mash.gov.al http:// www.izha.edu.al 